\title{
Capacity Development for Internal and External Auditors in the Complex Adaptive System of Higher Education in Vietnam
}

\section{Everard van Kemenade}

\section{Article History}

Received: 20 November 2020

Accepted: 02 February 2021

Published: 30 March 2021

\section{Keywords}

Reviewer training, reviewer attitude, quality paradigms, emergent paradigm

\author{
Senior lecturer and researcher on Quality Management and Change, Utrecht \\ University of Applied Sciences, Utrecht, The Netherlands \\ Email: everard.vankemenade@hu.nl
}

\section{INTRODUCTION}

Higher Education (HEd) all over the world is facing plentiful challenges such as growing demand and increasing competition worldwide. Blended and online education is booming, especially in these Corona-times, which put education quality under pressure. Maintaining quality in higher education institutes is a challenge. The solution that is chosen in most countries is accreditation. However, again, the development and implementation of a Quality Assurance (QA) system is not easy. One of the roadblocks is the resistance from academics.

Stemming from forty years of experiences all over the world, this article suggests three key points to pay attention to in the further development of a QA system specifically in Vietnam: continuing competency development of external auditors (in this article refered by the term 'auditor', reviewers, surveyors or assessors, not related to financial auditing, but to the internal and external peer review and on-site investigation process in higher education), the establishment of an internal auditing system within each Higher Education Institute (HEI) and emergent implementation of the QA system. Before discussing in details these suggestions, some insights into the situation in Vietnam are provided below.

\section{Background}

As a trainer and consultant, I have worked in Vietnam from 2004 till 2009. I started capacity development in quality and especially in quality management systems at Can Tho University. Together with Do Van Xe, Vice Rector at the time, the model that was developed by seven Higher Education Institutes in the Netherlands, based on the Excellence Model from the European Foundation for Quality Management (EFQM) was translated into Vietnamese. Later I was one of the consultants active in the ProfQim project that helped five Vietnamese universities to establish their Quality Assurance Centres. I was assigned to Thai Nguyen University and also trained people responsible for quality in all five universities within the project as well as from Ministry of Education and Training. I helped to develop the first accreditation standards in Vietnam and to train the first Vietnamese reviewers and higher education 
leadership. In 2009, however, Ministry of Education and Training (2009) stated: "While Vietnam higher education system is developing rapidly and on a large scale, the Education Ministry's management is failing to keep pace and higher education management is lagging behind".

In general, it can be stated that the accreditation system in Vietnam fits within the empirical paradigm of control and measurement. Hayden and Lam (2007) state that a culture of centralized planning and bureaucratic decisionmaking is deeply rooted across most areas of public service provision in Vietnam. They do report a desire by the central government to decentralize decision-making accountability to Higher Education Institutions for the purposes of achieving greater efficiency and effectiveness in the use of resources; and on the other hand, there is also a desire by the central government to retain control of the socialist orientation of higher education and of the deployment of the sector within a framework of centralized national economic management. As a result, as Ho and Berg (2010) states "in Vietnam, the activities of accreditation and quality assurance are not so much for the purpose of institutional assistance in their efforts toward improvement but rather represent a process of identifying and ranking good institutions versus poor ones".

Since then, significant achievements have been gained. Nguyen and Ta (2018) argue that the influence of accreditation contributes significantly to enhancing the university's quality of teaching, learning, research and management. They state that the implementation of the national compulsory accreditation scheme has encouraged the investigated institution and programmes to implement management processes designed to improve quality. Nguyen (2017) adds that the accreditation process has created significant improvements in the university's management of learning programmes, teaching activities, lecturers and staff, students and student support, and facilities. The involvements of overseas accreditation agencies have had positive impacts on the local quality assurance system in Vietnam.

Nguyen, Ta and Nguyen (2017) mention five lessons learned:

Lesson 1: External quality assurance agencies should be independent from the Ministry of Education and Training.

Lesson 2: International collaboration is necessary for every stage in the development of the quality assurance system.

Lesson 3: Human resources development in quality assurance should always be a great concern.

Lesson 4: Professional development and capacity building for quality assurance staff play an important part in the sustainable development of higher education quality assurance.

Lesson 5: Creating quality culture and developing internal quality assurance system are crucial for the institution's quality enhancement.

Nguyen (2018) concludes that the quality assurance mechanism has not been finalised. He mentions the following issues: inadequate human resources for higher education accreditation system, unsatisfactory self-evaluation reports and lack of qualification and experience of many auditors. The focus should be on human resource development and capacity development in higher education accreditation, particularly at macro (national) level (Nguyen, Evers and Marshal, 2017). Later Pham (2018) states that the lack of any attempts to improve competence of the reviewing team was barriers to education in Vietnam.

My conclusion is that all these years Vietnamese Higher Education has been very much controlled, very much led by the Empirical Paradigm mentioned above, and that auditors have been trained in that way of thinking.

In Van Kemenade et al. (2009) we tried to understand what was happening and presented five lessons learned from the ProfQim project in the form of recommendations:

1. Encouraging strong leadership;

2. Creating a climate of trust based on transparency;

3. Taking advantage of the ProfQim's unique national network;

4. Linking with student learning outcomes and graduate profiles;

5. Ensuring institutional autonomy.

To elaborate on the last lesson learned of the Profqim project, that autonomy should be ensured, I quote: "Quality assurance is focused in a process of continuous improvement within an institution through internal and external assessments. Therefore, another vital aspect to the success of the Quality Assurance Centers sustainability is to guarantee sufficient autonomy and self-regulatory capacity within the HE institutions. If, - after getting externally assessed and evaluated- the HE institution is unable to follow up the results and recommendations of the external evaluation, there is no point to even start the Quality Assurance process" (Van Kemenade et al., 2009, p. 7). Self- 
regulation cannot be forced upon. It is a learning process, an emerging process in a complex environment. It is amazing what emerges (unplanned) from the uncertainty and disorder. We can conclude that Higher Education in Vietnam is a Complex Adaptive System (CAS), which does not fit within the above mentioned three paradigms. What about quality management in a CAS?

\section{LITERATURE REVIEW}

Regarding quality management, Van Kemenade and Hardjono (2019) discern different quality paradigms, different lenses to look at quality: the Reflective Paradigm, the Empirical Paradigm and the Referential Paradigm. We shortly describe each of the quality paradigms with their own definition of quality and characteristics. Presence of the paradigms in Vietnamese higher education is suggested.

Lenses to look at quality

The Reflective paradigm: Quality is subjective

Vinkenburg (2006) introduces what we call the Reflective Paradigm. In the Reflective Paradigm everyone has his own reality that can be different tomorrow from today. This paradigm looks for the difference, makes it explicit and reflects on it. Knowledge is gathered (inductively) by telling and listening to stories, by conversations, group meetings, inner conversations. This paradigm reflects and philosophizes: What did I do well and what did I do wrong and why? In its research, we recognize the philosophy of subjectivism.

During the Corona crisis, the reflective paradigm would be illustrated through the example of the Dutch government: intelligent lockdown. Only a few rules (1,5 meters distance, washing your hands; staying at home if you are sick) and no legal enforcement. It is up to the people how to handle the specific situation. The Reflective Paradigm is subjective. This is where the lecturer is 'the King in the classroom', where only he or she knows what is best in the discipline, the curriculum. Lecturing for hundreds of students, students that are considered the last to be able to evaluate the quality of one's education. At his best, quality is discussed between colleagues. The lecturer might reflect on his performance and even might ask at the end of a course what went well and what did not. Hopefully he also takes action, although we often see that the powerpoints that were unreadable are used next year again, because the lecturer did not have the time to adjust. In the higher education of the past we recognize this paradigm worldwide, also in Vietnam.

The Reference paradigm: Quality is fitness for use

Of course, in the long run the situation described above is not sustainable. It is logical that surely when the HEd sector grows and external (international) players get into the field, more influence on the quality is needed. Influence from governmental agencies increases, some innovative Higher Education Institutes take their own responsibility for quality. To achieve this, quality models were designed, frameworks of reference in which criteria or areas to address are mentioned. We call it the Paradigm of Reference. In its research, we recognize the constructivism philosophy. This paradigm prescribes what standards need to be met or what score one should achieve to get an award or certificate. The quality knowledge is gathered (deductively) searching for observable, real cases that prove that the organisation meets the standards. Theoretically, quality can be defined as fitness for purpose or fitness for use (Juran, 1951).

The Paradigm of Reference values, certifies and accredits using models such as the ISO9000-series, Joint Commission International Accreditation in Healthcare, the Balanced Score Card, the EFQM Excellence model or the National Malcolm Baldrige Quality Award. National Awards are installed all over the world to motivate companies to keep improving. This is where the TQM paradigm fits in. Quality management in this paradigm focuses on quality improvement.

Unfortunately, there is no universal model to cope with the Corona-crises. Countries respond differently with different success. We do recognise the Referential Paradigm in quality management e.g. in the ASEAN Quality Assurance Framework for Higher Education and in systems of Quality Control such as national accreditation. HEI's write self-evaluation reports, reviewers come and perform in site visits. We have seen this development in HEd all over the world, also in Vietnam.

The Empirical Paradigm: Quality is what can be measured

In the Netherlands, the governmental accreditation system that started as an open system with autonomy for HEI's to focus on specific quality issues along the way got further and further detailed and standardised in its requirements. We see the occurrence of the Empirical Paradigm. The Empirical Paradigm derives its name from its methodology. In its research, we recognize positivism as its philosophy. Knowledge about the reality is gained by experiencing here and now, by sensory perception. It is evidence based. Knowledge is gathered (inductively) by 
measurements and its objective results are expressed in quantities, i.e. sizes and numbers. The Empirical Paradigm lives on rules and works top down. It registers and controls: to measure is to know.

In the Corona crisis an 'empirical solution' would be: immediate top down enforced total lockdown. You can recognize the empirical paradigm in the use of wordings such as assessment, measurement, quality assurance. Quality in Higher Education becomes ticking boxes. External reviewers become inspectors. Standards are undebatable. We have seen this development from the reference to the empirical paradigm in many Western countries. If this has not happened in Vietnam yet, there always is a risk it will.

None of these paradigms, however, cope with the complexity of the higher education systems.

\section{RESEARCH METHODS AND RESULTS}

To search for quality management in complex adaptive systems, a dynamic orientation in scientific literature is executed using the berry-picking method (Bates, 1989). Bates' model integrates a biological and a socio-cultural perspective to argue that, in practice, information seeking does not follow a systematic search process but more commonly takes the form of "berry picking" or finding information bit by bit using a range of sources. In doing so, Higher education as a Complex Adaptive System leads to the Emergence Paradigm.

The Emergence Paradigm

In the first paragraphs of this article, three quality paradigms are presented. However, there is a fourth paradigm, the emergence paradigm, that fits quality management specifically in complex adaptive environments, when the situation is unplanned and uncertain (see Figure 1).

\section{Four quality paradigms}
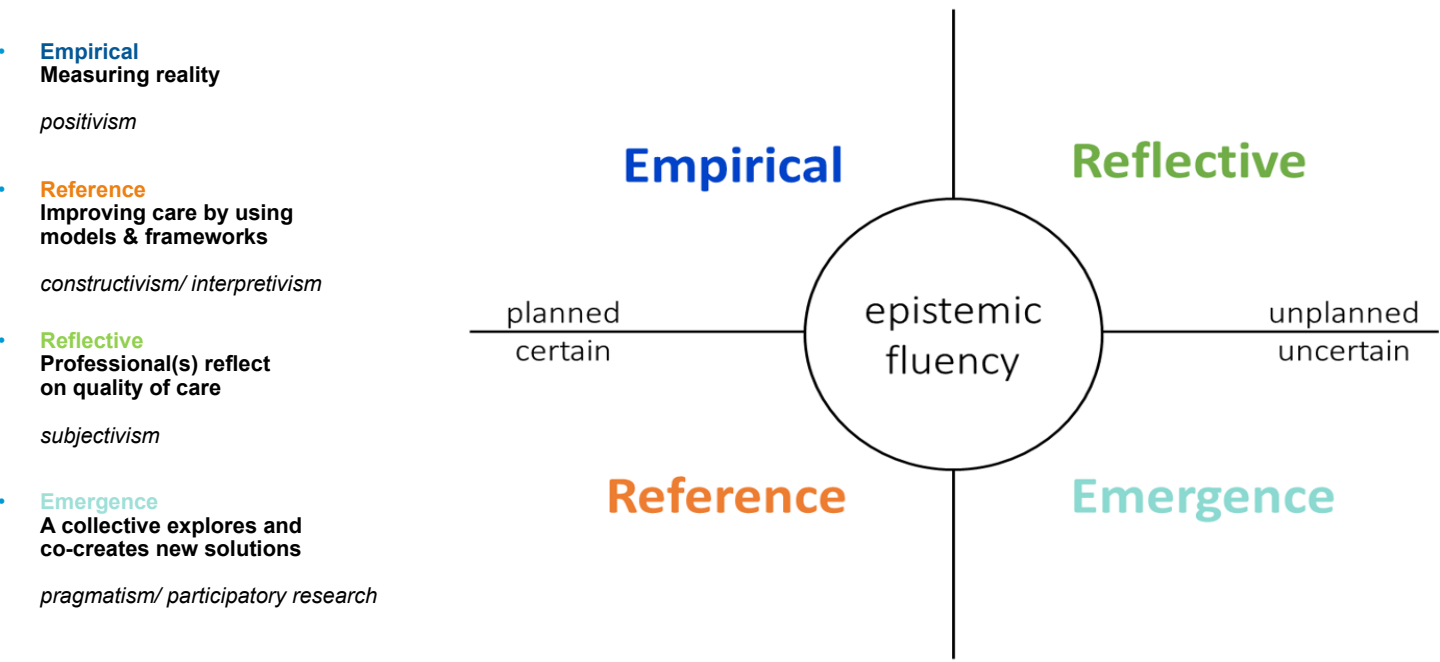

Figure 1. The four quality paradigms

The Emergence Paradigm has the potential to prevent quality management programs to fail. This quality paradigm fits in the current era of continuous changes and complexity (as Miller and Cangemi, 1993 request). It has pragmatism as its research philosophy, using participatory and action research methods. Emergence is a concept from system theory. It relates to the development of complex organised systems, that have characteristics that are not visible by reduction of the composing parts. "While some experts are familiar with development in one field, such as artificial intelligence, nanotechnology, big data or genetics, no one is an expert on everything. No one is there for capable of connecting all the dots and seeing the full picture" (Harari, 2015). Emergence is the process where new characteristics come to existence through interaction between simple, small entities that do not have these characteristics like the self-organisation of ants. Many ants together show a collective intelligence that individual ants do not possess. Another example is a swarm of starlings. Each starling in a swarm follows simple rules: staying at a distance from one another, staying in contact with seven other colleagues and interacting with these. Emergence provides greater buy-in by employees and it continuously relates to the context, so it will offer context specific designs (as Asif et al, 2009 request).

Lifvergen et al. (2011) make a fundamental distinction between planned change and emergent unplanned change (see Table 1). 


\begin{tabular}{|l|l|}
\hline Planned change & Emergent change \\
\hline $\begin{array}{l}\text { Almost always accompanied by } \\
\text { unexpected consequences }\end{array}$ & $\begin{array}{l}\text { The outcome is not the preconceived } \\
\text { solution, but the development of the } \\
\text { most appropriate solution for the } \\
\text { stakeholders concerned }\end{array}$ \\
\hline Appropriate for structural changes & Appropriate for cultural changes \\
\hline Appropriate for economic-based change & $\begin{array}{l}\text { Appropriate for organizational capacity } \\
\text { building }\end{array}$ \\
\hline $\begin{array}{l}\text { Appropriate for new organizational } \\
\text { structures }\end{array}$ & $\begin{array}{l}\text { Appropriate for change process target- } \\
\text { ing work processes }\end{array}$ \\
\hline
\end{tabular}

Table 1. Planned change versus emergent change according to Lifvergen et al. (2011)

In the Corona-crisis, the emergence paradigm would bring together experts from all fields of society (doctors, nurses, economics, artists etc.) to have a continuous dialogue on what is needed when and where. All sorts of novelty would occur. An ice truck becomes a morgue. An ATM leads to a free rice machine. In higher education before Corona, e-learning was hard to implement, now it is booming and will be used more than ever, also after the Coronacrisis. Everyone has meetings in Microsoft Teams or Zooms. Working from home is and will be more applied, leading to less pressure on the traffic and our environment. Conferences are online. It is the higher education collective that co-creates new solutions.

\section{Focus on audit}

In this article the author would like to focus on the exemplary topic of reviews in the accreditation system from the emergence perspective. Van Kemenade (2009) describes the willingness of higher education professionals in the Netherlands and Dutch speaking Belgium to contribute to a compulsory accreditation system. In general, academics claim to feel like outsiders in the accreditation process and its development. This is confirmed by Rosa et al (2019): "This analysis reveals a moderately positive attitude of academics towards accreditation, reflected in an only moderate knowledge of the process as well as in a mild agreement with its characteristics and implementation features. This suggests that there is room for improvement to bring this quality assurance mechanism closer to academics".

In Van Kemenade (2019), the actors and several instruments are mentioned that can be used to create the required change process towards better acceptance of the accreditation system. Instead of control, force, the empirical paradigm, we'd like to promote the emergence paradigm as philosophy for change. The next paragraph relates to the actors to bring into the field, the following is about the instruments used.

Emergence and the actors.

Emergence occurs if the actors are interdependent (Palmberg, 2009a,b; Ellis and Herbert, 2011; Bratman, 2014). In the Emergence Paradigm, one would organize interactions between all stakeholders within HEI's, MOET, GDETA, the World of Work, students, international organisations and experts.

Emergence occurs by diversity of the elements or actors. Emergence is also enhanced by diversity because of the greater interactions and richer patterns (Holden, 2005). Juriado and Gustafsson (2007) state that the emergent communities of practice in their case study emerged by "diversity, the number and the fluidity of the individuals and organisations involved." This requires a deep study of the participation of experts in the audit teams.

Emergence and instruments

Emergence is fostered by improvisation. Haenisch (2011, p. 187): The term 'emergence' points to the characteristics of a collective creativity that cannot be understood in terms of individual accomplishment or ability, but instead as a social practice in which the central authority of artistic authorship is transformed into an aesthetic collaboration, one that is not reducible to a simple "sum" or chain of individual creative contributions, but that brings about an additional value, thus contributing to an improvisation's success. Within audit teams, improvisation need to be supported.

McBeth (2002) talks about the need for creative discourse as a means for emergence. Snowden and Boone (2007) call it 'dissent and formal debate'. Leaders must create the conditions: 'they have to probe, sense and respond'. "Because outcomes are unpredictable in a complex context, leaders need to focus on creating an environment from which good things can emerge, rather than trying to bring about predetermined results and possibly missing opportunities that arise unexpectedly" (Snowden and Boone, 2007). Ellis and Herbert (2011) advise management to ensure that lines of communication flow across the network. Fundin et al. (2019) stress the importance of creativity. 
Van Kemenade and Hardjono (2019) prefer to talk about the creative dialogue. Kelly (1994, p. 469) mentions 'growth by chunking': "The only way to make a complex system that works is to begin with a simple system that works. Attempts to instantly install highly complex organization - such as intelligence or a market economy - without growing it, inevitably leads to failure." Auditors within an audit team need to create such a creative dialogue with academics and management of the HED institutes.

Ellis and Herbert (2011) suggest applying simple design principles because they turn into rules. Palmberg (2009) quotes Zimmerman et al. (1998, p. 26) who state: "It does show that simple rules - minimum specifications - can lead to complex behaviors. These complex behaviors emerge from the interactions among agents, rather than being imposed upon the CAS by an outside agent or explicit, detailed description". Many accreditation systems have a lot of accreditation standards and audits have to follow up the conformance to each of them. That might not be the best way to go ahead.

Auditor

Van Kemenade (2009) puts emphasis in this respect on the quality of the auditor in an accreditation process, just like Nguyen (2018) wants. The conclusions of Van Kemenade's research are that professionals are willing to contribute to an accreditation process because they agree accreditation has added value. They have the conviction specifically that the review could contribute to quality improvement. However, there are impediments to this willingness within the accreditation process, the professional himself and in the organization (see Figure 2). If the process is not motivating or if the professional is not loyal to the organization or if the organization does not give enough management support, the accreditation process might not be successful. In the respect of our research question, regarding the acceptance of the accreditation system by professionals, the impediments in the accreditation process and especially regarding the auditor are interesting. One of the conclusions of the Delphi-study is that the auditor should not have control as a dominant value. The behavior of auditors is, according to the participants in the Delphi study, too often unpredictable. Members of the team have different interpretations of the standards. Some auditors have an offensive attitude that makes that interviewees do not dare to be vulnerable and open their mind for feedback. Auditors can easily be the cause of resistance. Professionals prefer to have a dialogue with peers who received additional training in the accreditation process. In fact, this implicates that an auditor should not just deliver an output like a concise and clear report, but that he also has a responsibility towards the outcomes of his intervention: what the receiving professionals actually do with the information and to what extent that really leads to improvement. The auditor needs to realize that he has an impact on the professionals. The success of an accreditation system depends on the acceptance of the review and of the auditor. Bad performance of auditors can have great consequences for the acceptance of the accreditation system and that performance largely depends on way the auditor behaves. Especially when the dominant value of an auditor is to control (especially, if he works from the empirical paradigm), resistance occurs. A bad auditor may result in what Barrows (1999) calls - dramaturgical compliance: the interviewee performs in a play and tells the auditor, not the truth, but what he wants to hear.

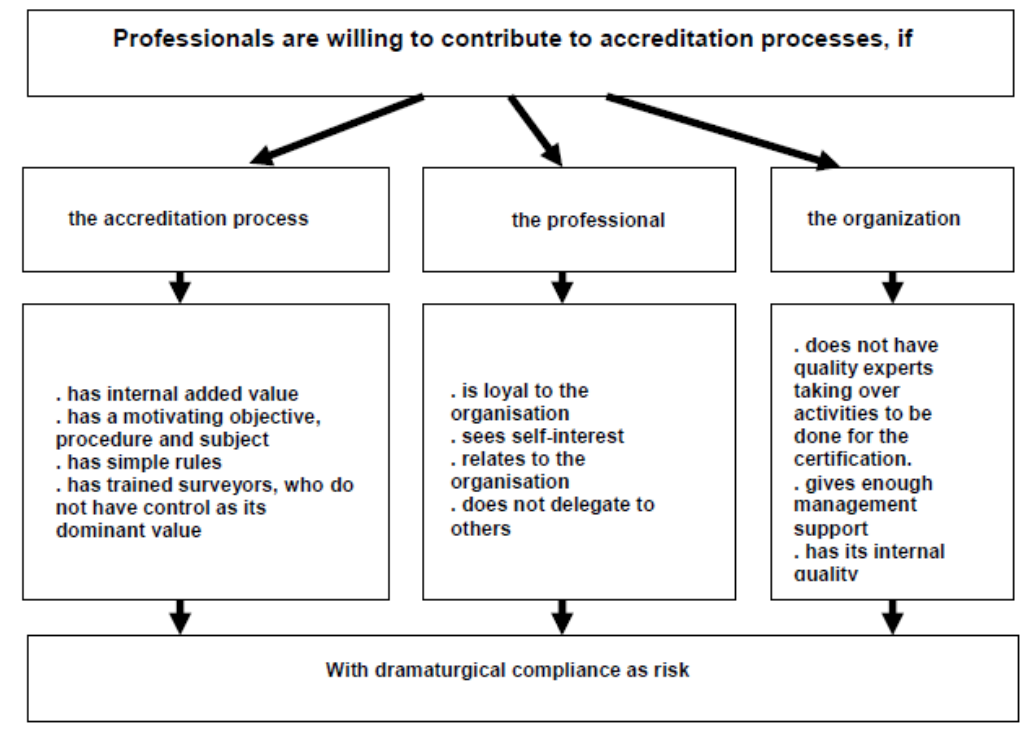

Figure 2. Willingness of Professionals to Contribute to a Mandatory Accreditation System 


\section{Auditor Competences}

In terms of competences for reviewers (or assessors, inspectors or auditors), again, there is not much literature. Lancaster et al (2010) studies the extent to which auditor training and active involvement in accrediting other facilities translates as a value-added resource for the auditor in her or his usual professional role or for the facility in which an auditor is regularly employed. They do not pay attention to the content of the training. Shaw (2000) shows that an auditor should be selected on the basis of identification and definition of the components of employment, taking advantage of a set of competencies and qualifications, but does not specify what these should be. Teymourzadeh et al. (2016) hold interviews with auditors in Iran to study the auditor selection, training, support, and stimulation, which is called the auditor management accreditation program. Important conclusions by the respondents are that the first motivator for auditors is financial and that in the case under study, the auditors are neither well selected, nor properly trained. Some of the main personality-behavioral characteristics considered by the respondents of the research done by Teymourzadeh et al. (2016) are included for the training program and for use as a reference document when preparing for or taking part in a survey. Little is said about what exactly the required competences are. Cuang and Inder (2009) mention that Tan et al. (2002) suggest that when assigning auditors to highly complex tasks, it should be ensured that the reviewers have the requisite knowledge as well as the appropriate motivational level. Reviewers assigned to significant review responsibilities should possess the knowledge, skills, and abilities to effectively fulfil those tasks. Teymourzadeh et al. (2016) include communication skills, flexibility, confidence, accountability, honesty, open-mindedness, and impartiality. Lee et al. (2016) focus on self-efficacy. They conclude that high selfefficacy typically leads to higher audit quality with immense effects on an individuals' motivation, efforts, persistence and performance. Professional development and audit quality have found to have a positive correlation. High profession growth typically leads to higher audit quality. Therefore, self-efficacy and professional development affect audit quality.

\section{Auditor attitude}

In training often a distinction is made between knowledge, skills and attitude. To improve the quality of interaction, Maas (2000) stresses the importance of attitude. Attitude is the most important to overcome fear and nervousness on the one hand and to prevent dramaturgical compliance and a Hawthorne effect. An attitude is, according to Eagly and Chaiken (1993), a psychological tendency that is expressed by evaluating a particular entity with some degree of favor or disfavor. An attitude has an affective component (how we feel about something or somebody), a cognitive component (how you think, what you believe about something or somebody) and a behavioral component (how we behave accordingly). However, there is evidence that the cognitive and affective components of an attitude do not always match with behavior.

Van Kemenade and Al-Salmani (2019) define seven attitudes that make the difference for auditors: (1) Intention; (2) Justice; (3) Sincerity; (4) Conscious of self-improvement; (5) Trust; (6) Trustfulness; (7) Patience.

Capacity development of reviewers, especially regarding their attitude, can largely influence the effectiveness of an accreditation system, also in Vietnam. Besides, experiences all over the world confirm that internal auditing and training of internal auditors can have an immense effect on the establishment of a quality culture within HEI's (Lesson 5 mentioned above in Nguyen et al., 2017). Especially when the external auditing is expanded with an internal audit equivalent.

\section{DISCUSSION AND CONCLUSIONS}

The accreditation process in higher education can be more effective if academics are willing to be open and reveal the strengths and weaknesses of the organization; if they are not afraid or nervous engaging in the review; if they do not perform dramaturgical compliance or if there is no sign of a Hawthorne effect. That requires specific reviewer' attitudes and a specific audit system.

Our research from the literature review brought us to 7 attitudes. The attitude of the reviewers is a critical success factor for accreditation. However, the success of the review and the feedback given depends on more than just the attitude of the auditor. When we look at the auditor, personal characteristics, education, audit experience and audit training can influence the quality of an auditor. And the success depends on the strength of the survey team as a whole.

Furthermore, the quality of the standards and the scoring system, the organization of the site visit have an impact on the outcome. The success also depends on the way the interviewees are able (and trained) to accept feedback. And the outcome of a survey stays in the first place the responsibility of the organization itself. The audit system should be expanded towards internal audits in every university. The power of an internal audit is a catalyst for the 
establishment of a quality culture. But the reviewer has an important role in the improvement process of an organization that is to be accredited.

Improving the quality of the on-site review system is crucial for the effectiveness of accreditation. One could try to implement the required change towards an improved system of internal and external review from each of these mindsets. If you would apply the Reflective Paradigm, one could try organizing sessions with professionals all over the country, organizing conferences and workshops like this to discuss the needs together and learn from each other's experiences with auditing. There is nothing wrong with that, but that will not bring the breakthrough that is needed. One could further develop the existing audit model using national and international experts (lesson 2, Nguyen et al., 2017). That perspective from the Reference Paradigm perspective might help. If you would apply the Empirical Paradigm, one would define the knowledge, skills and attitudes that an auditor (more likely an inspector in that mindset) needs, one would develop a training program and cascade that from the top, i. e. the Ministry, down to every organization. However, the question is if that would really create the breakthrough needed. Dao (2015, p. 259) does a case study and concludes: "Despite an appreciation of the need for reform, and the desire of many individual actors to pursue reform, the imprint of State control and top-down management, together with a very depleted institutional financial capacity and a lack of proper appreciation of the nature of institutional quality assurance, meant that not much at the University could be changed. This conclusion seems likely to apply also to the whole of the public higher education system in Vietnam". Madden (2013) conducts a policy document analysis and key informant interviews showing that the implementation of QA policies in Vietnam is an example of how one developing country walks the line between state-centric values and neoliberal principles. Nguyen and Robinson (2015) identify the cultural conditions that have most shaped, and continue to shape the management of continuous improvement in Vietnam. They do confirm that a very strong top-down management approach seems to be necessary. But, as they say, mainly to jump-start continuous improvement in Vietnamese organizations. Madden (2013, p. 202) concludes: "The ASEAN way may provide a pragmatic approach to QA that blends a limited fitness for purpose definition of quality with standards-based quality management". And: 'Institutional differentiation and institutional autonomy could be approached in the ways in which public universities can carve out their unique roles in driving the economic development of the country".

That is what we call 'epistemic fluency' (see figure 1), the capacity to understand, combine and switch from the different paradigms, when needed. The emergent paradigm could be the next step for this moment, giving way for the autonomy of the HEI's in Vietnam (since it focuses on self-organization) and more influence of the academics as well (Van Kemenade, 2009; Rosa et al., 2019). It would mean a breakthrough in the way Higher Education is led. It would be the collective that co-creates new solutions.

Research limitations/implications: The Vietnamese situation has been studied from an outsider perspective by the analysis of a limited amount of articles. That might have created bias.

\section{REFERENCES}

Asif, M., Bruijn, E. J., de, Douglas, A. \& Fisscher, O.A.M. (2009). Why quality management programs fail: a strategic and operations management perspective. International Journal of Quality \& Reliability Management, $26(8), 778-794$.

Barrows, M. J. (1999). Quality-management Systems and Dramaturgical Compliance. Quality in Higher Education, 5(1), 27-36.

Bates, M. J. (1989). The design of browsing and berrypicking techniques for the on-line search interface. Online Review, 13(5), 407-431.

Bratman, M. (2014). Shared Agency: A Planning Theory of Acting Together. Oxford University Press, New York, NY.

Cuang, S. \& Inder, K. (2009). An effectiveness analysis of healthcare systems using a systems theoretic approach. BMC Health Service Research, 9, 195.

Dao, K. Van, (2015). Key challenges in the reform of governance, quality assurance, and finance in Vietnamese higher education - a case study. Studies in Higher Education, 40 (5), 745-760. http://dx.doi.org/10.1080/03075079.2013.842223

Eagly, A. H. \& Chaiken, S. (1993). The psychology of attitudes. Fort Worth, TX: Harcourt.

Ellis, B. \& Herbert, S. I. (2011). Complex Adaptive Systems (CAS): an overview of key elements, characteristics and application to management theory. Informatics in Primary Care, 19(1), 33-37. 
Fundin, A., Backström, T. \& Johansson, P. E. (2019). Exploring the emergent quality management paradigm. Total Quality Management \& Business Excellence, 32(5-6), 476-488. https://doi.org/10.1080/14783363.2019.1591946

Haenisch, M. (2011). Emergence: on a theoretical term in current improvisation research, (translated by Noble, R.) in Beins, B., Kesten, C., Nauck, G. \& Neumann, A. (Eds). Echtzeitmusik Berlin. Selbstbestimmung einer Szene. Self-Defining a Scene, Wolke V.-G, Hofheim am Taunus, 186-200.

Harari, Y. N. (2016). Homo Deus, A Brief History of Tomorrow. Vintage, London.

Hayden, M. \& Lam, T. (2007). Institutional autonomy for higher education in Vietnam. Higher Education Research \& Development, 26(1), 73-85.

Ho, M. P. T. \& Berg, D. (2010). Educational leadership challenges: Vietnam's system of Higher Education. Asia Leadership Roundtable 2010, Asia Pacific Centre for Leadership and Change Hong Kong Institute of Education.

Holden, L. M. (2005). Complex adaptive systems; a concept analysis. Journal of Advanced Nursing, 52(6), 651-657.

Juran, J. M. (1951). Quality Control Handbook. McGraw-Hill, New York, NY.

Juriado, R. \& Gustafsson, N. (2007). Emergent communities of practice in temporary inter-organisational partnerships. The Learning Organization, 1(1), 50-61.

Kelly, K. (1994). Out of Control: The New Biology of Machines, Social Systems and the Economic World. AddisonWesley, New York, NY.

Lee, S-C., Su, J-M., Tsai, S-B. \& Lu, T-L. (2016). A comprehensive survey of government auditors' self-efficacy and professional development for improving audit quality. Springer Plus, 5(1), 1263.

Lifvergen, S., Docherty, P. \& Shain, A.B.R. (2011). Toward a sustainable healthcare system: transformation through participation, in Mohrman, S.A., Shani, A.B.R. and Worley, C. (Eds). Organizing for Sustainable Effectiveness, Emerald Books, Bingley, 99-125.

Maas J. (2000). Professionality: management of professional and professional organizations. Kwaliteit in Praktijk, B1-5, Kluwer, Deventer.

Macbeth, D. (2002). Emergent strategy in managing cooperative supply chain change. International Journal of Operations \& Production Management, 22(7), 728-740.

Madden, M. (2013). Walking the line: quality assurance policy, development and implementation in Vietnam. The International Journal of Higher Education Research, 67, 91-104. doi:10.1007/s10734-013-9642-8

Miller, R. \& Cangemi, J. (1993). Why total quality management fails: perspective of top management. Journal of Management Development, 12(7), 40-50.

Ministry of Education and Training (2009). Special Report for the Minister's presentation at the High Value Education Forum to be hosted by the Vietnam Consulate General (SF) in San Francisco, November 16.

Nguyen, H. C. \& Ta, T. T. H. (2018). Exploring impact of accreditation on higher education in developing countries: a Vietnamese view. Tertiary Education and Management, 24(2), 154-67. https://doi.org/10.1080/13583883.2017.1406001

Nguyen, H. C. (2017). Impact of International Accreditation on the Emerging Quality Assurance System: The Vietnamese Experience. Change Management: An International Journal, 17(3). http://dx.doi.org/10.18848/2327-798X/CGP/v17i03/1-9

Nguyen, H. C. (2018). How to Fulfil Vietnam's Higher Education Accreditation Strategic Plan 2017-2020. The International Journal of Educational Organization and Leadership, 24(3/4). http://doi.org/10.18848/23291656/CGP/v24i03/17-25

Nguyen, H. C., Evers, C., \& Marshall, S. (2017). Accreditation of Vietnam's higher education: Achievements and challenges after a dozen years of development. Quality Assurance in Education, 25(4), 475-488, https://doi.org/10.1108/QAE-11-2016-0075

Nguyen, H. C., Ta, T. T. H. \& Nguyen, T. T. H. (2017). Achievements and Lessons Learned from Vietnam's Higher Education Quality Assurance System after a Decade of Establishment. International Journal of Higher Education, 6(2), 11-17.

Nguyen, P. \& Robinson, A. (2015). Continuous improvement in Vietnam: unique approaches for a unique culture. Journal of Asia Business Studies, 9(2), 195-211. https://doi.org/10.1108/JABS-11-2014-0093

Palmberg, K. (2009a). Beyond process management: exploring organizational applications and complex adaptive systems. Doctoral thesis, Luleå University of Technology, Department of Business Administration and Social Sciences, Division of Quality Management. 
Pham, H. T. (2018). Impacts of higher education quality accreditation: a case study in Vietnam. Quality in Higher Education, 24(2), 168-185.

Rosa, M. J., Cardoso, S. \& Videira, P. (2019). Is accreditation 'on the right track'? The views of Portuguese academics. Tertiary Education and Management, 26, 185-197. https://doi.org/10.1007/s11233-019-09048-7

Shaw, C. D. (2000). External quality mechanisms for health care: summary of the expert project on visitatie, accreditation, EFQM and ISO assessment in European Union countries. External Peer Review Techniques. European Foundation for Quality Management. International Organization for Standardization. International Journal for Quality in Health Care, 2(3), 169-75.

Snowden, D. J. \& Boone, M. E. (2007). A leader's framework for decision making. Harvard Business Review, 85(11), 68-76.

Tan, H. T., Nguyen, T. B. \& Mak, B. W. (2002). The effects of task complexity on auditors' performance: the impact of accountability and knowledge. Auditing: A Journal of Practice \& Theory, 21(2), 81-95. https://doi.org/10.2308/aud.2002.21.2.81

Teymourzadeh, E., Ramezani, M., Arab, M., Foroushani, A. R., \& Sari A. A. (2016). Surveyor Management of Hospital Accreditation Program: A Thematic Analysis Conducted in Iran. Iranian Red Crescent Medical Journal, 18(5): e30309. http://doi.org/10.5812/ircmj.30309

Van Kemenade \& Al-Salmani (2019). Health Care Surveyor: Virtues and Islamic Work Ethics. International Journal of Research in Business Studies and Management, 6(18), 1-15.

Van Kemenade, E. (2009). Certification, Accreditation and Professionalism. Retrieved from: https://eburon.nl/product/certificering_accreditatie_en_de_professional

Van Kemenade, E. A. \& Hardjono, T. W. (2019). Twenty first century total quality management: the emergence paradigm. TQM Journal, 3l(2), 150-166.

Van Kemenade, E., Koeslag, J. C. \& Mangili-Vincent, S. (2009). Lessons learned from the Vietnam Netherlands Higher Education Project on Quality Assurance. Internal document ProfQim project, Hanoi.

Vinkenburg, H. (2006). Dienstverlening; paradigma's, deugden en dilemma's. Kwaliteit in Praktijk, Kluwer, Deventer, 1-35.

Zimmerman, B., Lindberg, C. \& Plsek, P. (1998). Edgeware: Insights from Complexity Science for Health Care Leaders. VHA, Irving, TX. 